\title{
Development of New Design of Specimens for Friction Determination in Metal Forming
}

\author{
Rahul Thakur ${ }^{1}$, Manoj Gangwar ${ }^{2}$, Prabhash Jain ${ }^{3}$ \\ ${ }^{1}$ (M.E. Scholar, Department Of Mechanical Engineering, B.U.I.T, Bhopal, M.P., India) \\ ${ }^{2}$ (Prof., Department Of Mechanical Engineering, O.I.S.T, Bhopal, M.P., India) \\ ${ }^{3}$ (HOD, Department Of Mechanical Engineering, B.U.I.T, Bhopal, M.P., India)
}

\begin{abstract}
The main objective of this research is to find alternate specimens for friction determination, and develop their friction calibration curve. Finite Element simulation is carried out using these alternative specimens and friction calibration curves are generated. Result of these curves is compared with ring compression test. The result of this investigation shows that such alternative specimens may play important role in friction determination in absence of ring specimen. It is observed that the geometry of those specimens which consist any geometrical shape inside circle give very close friction values.
\end{abstract}

Keywords: Friction Coefficient, Metal Forming Process, Ring Compression Test, Finite Element

\section{Introduction}

Friction is defined as the resistance to the relative sliding between two bodies in contact under a normal load. Metal working and manufacturing process are significantly affected by friction, because of the relative motion and the force present between tool dies, and work pieces. Friction has significant effects on both the work pieces and process variables such as deformation load, metal flow, surface quality and internal structure of the product in metal forming processes. Therefore, the interface friction has to be understood and control. For effective friction control, effects of the deformation process variables, such as deformation speed, material type, and lubrication, must be treated together to investigate interaction effects among these variables. There are several methods developed for quantitative evolution of friction at the die/work piece interface in metal forming process. The most accepted one is to define a coefficient of friction, $\mu$, the coulomb law of friction expressed as $\tau=\mu$.p, where, $\tau$ is the frictional shear stress and $p$ is the normal stress. Among all common methods for measuring the friction coefficient, the ring compression test has gained wide acceptance. It was originated by Kunogi [1] and later improved and presented in a usable way by Male and Cockcroft [2]. This technique utilizes the dimensional changes of a test specimen to arrive at the magnitude of friction coefficient. When a flat ring specimen is plastically compressed between two flat platens, increasing friction results in an inward flow of the material, while decreasing friction results in an outward flow of the material as schematically shown in Fig.1. For a given percentage of height reduction during compression tests, the corresponding measurement of the internal diameter of the test specimen provides a quantitative knowledge of the magnitude of the prevailing friction coefficient at the die/ work piece interface. If the specimen's internal diameter increases during the deformation, friction is low; if the specimen's internal diameter decreases during the deformation, the friction is high. Using this relationship, specific curves, later called friction calibration curves, were generated by Male and Cockcroft relating the percentage reduction in the internal diameter of the test specimen to its reduction in height for varying degrees of the coefficient of friction as shown in Graph 1.

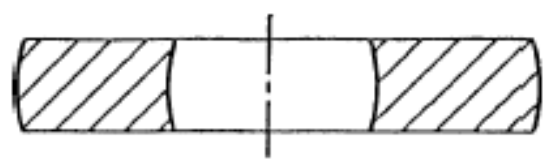

Low friction (good lubrication)

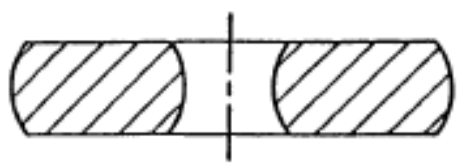

High friction (poor lubrication)

Fig. 1 Effect of friction magnitude on metal flow during the ring compression test 
Male and Cockcroft's standard ring geometry of 6:3:2 was used, and calibration curves are formed to ring geometries. Each ring geometry; has its own specific set of curves. The most common ring geometry is $6: 3: 2$ where the first number denotes the outer diameter; and the second number denotes the internal diameter while the last one is for height of the ring. Lee[3] developed a method to find the friction factor of the die/work piece interface for the forging process without the need for measurement of the shape changes of the work piece. Using the proposed model to predict the influence of die velocity on the friction factor showed that the friction factor decreases when the die velocity was increased. Bugini [4] developed FEM calibration chart for ring upsetting at room temperature when dealing with annealed Aluminum specimens of different height. The method allows the evolution of the friction coefficient affecting the plastic flow when Teflon films are interposed between dies and specimens. Hayhurst [5] proposed a new technique of calibration, which utilizes two test piece geometries, namely the solid cylindrical compression test piece and the ring compression test piece. It has been shown that it is possible to derive the true stress-true stain curve for the work piece materials; and, to calibrate the friction model. The geometrical changes of all test pieces carefully measured throughout the tests, for a range of four different friction conditions, dry friction, lubricant, lead metal and nylon, have been predicted with good accuracy using the true stress-true strain constitutive models; the two parameter friction model, and the finite-element analysis procedures. Sofuoglu and Rasty [6] address the dependency of the friction calibration curves obtained for the coefficient of friction, $\mu$, on such factors as material properties, strain-rate sensitivity, and barreling.

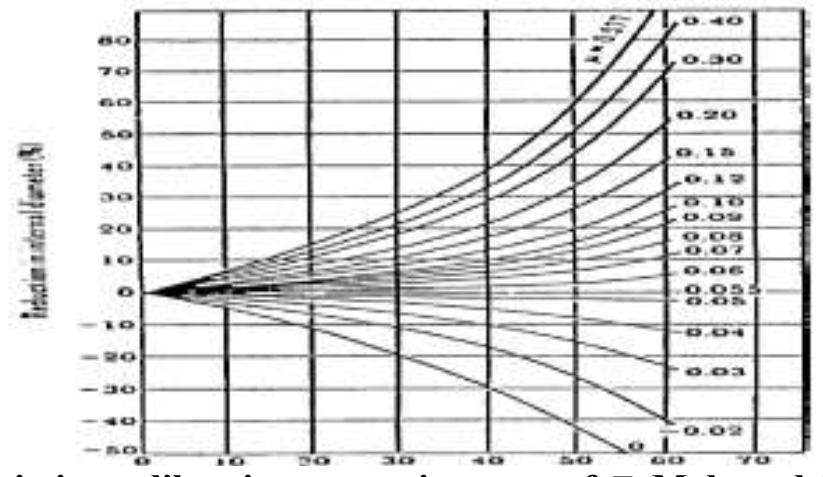

\section{Graph. 1 Friction calibration curves in terms of $\square$ Male and Cockcroft}

Black and white plasticine as soft (nonmetallic) modeling materials and aluminum, copper, bronze and brass as metallic materials were used to conduct a number of ring compression tests. The necessary material parameters of plasticine for the finite element analysis were obtained from a series of the compression tests. The elastic-plastic finite element code ABAQUS was then used to simulate the ring compression test in order to investigate the effect of the above factors on the friction calibration curves, for Aluminum material as shown in Graph.2 It is observed that very few attempts have been made to generate friction calibration curve using other geometrical shape specimens. Detailed study on how the friction calibration on specimens behave during deformation and what type of deformation take place on the FE deformed mesh has not been conducted.

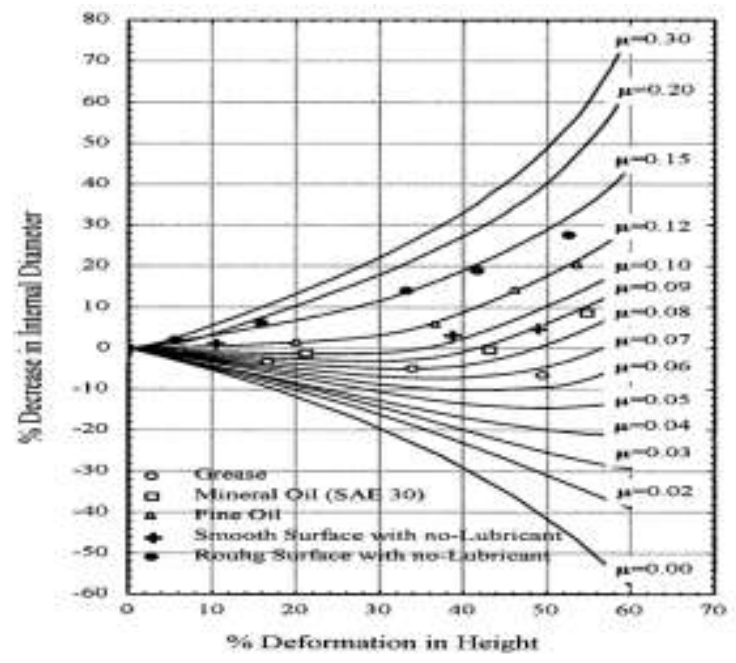

Graph. 2 Friction Calibration Curves for Aluminum material proposed by Sofuoglu [6] 
The deformation on other geometrical specimens and its dependency on the characteristics of ring compression test have not been crystallized so far. This could be studied in detail using finite element simulation and their experimental verification of friction calibration curve using ring compression test.

\section{Experimental Procedure}

In ring compression test, the geometry of ring specimen has proportion of outer diameter to inner diameter to height (OD : ID: Thickness) of $6: 3: 2$. In this study of friction calibration curve by ring compression test using three specimens developed:

The name of first specimen is circle in circle i.e. ring, the geometry of ring specimen has proportion of OD : ID : Thickness. Dimensions of the specimen are $40: 20: 13.33$. All dimensions in mm as shown in Fig.2

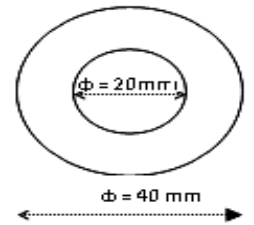

Fig. 2 Ring Geometry

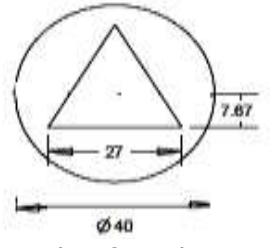

Fig. 3 Triangle in Circle

The name of the second specimen is Triangle in Circle. The geometry of Triangle in Circle has proportional of 40: 27: 13.33, all dimensional in $\mathrm{mm}$ are shown in Fig.3

The name of the third specimen is Square in Circle. The geometry of Square in Circle has proportional of 40: 17.27: 13.33, all dimensional in $\mathrm{mm}$ as Shown in Fig.4

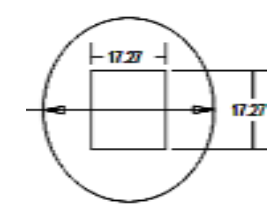

Fig. 4 Square in Circle

Compression test on the specimens are carried out using UTM, All the specimens are comp- ressed between $30 \%$ to $45 \%$. Percentage of compression and load applied on the specimens are shown in Table. 1

Table.1\% of Compression and Load requirement on the specimen

\begin{tabular}{|c|c|c|c|}
\hline S.No & Specimens & $\begin{array}{c}\text { Load Applied } \\
(\mathrm{KN})\end{array}$ & $\begin{array}{c}\% \text { of } \\
\text { Compression }\end{array}$ \\
\hline 1. & $\begin{array}{c}\text { Circle in Circle } \\
\text { (Ring) }\end{array}$ & 555 & 40.61 \\
\hline 2. & Triangle in Circle & 590 & 41.54 \\
\hline 3. & Square in Circle & 535 & 41.54 \\
\hline
\end{tabular}

\section{Finite Element Model}

Finite element analyses of the compression test are carried out in order to study the deformation behavior with respect to friction. FE simulation is carried out using ABAQUS [7] software. The interaction of platen and specimen is accounted using CONTACT command, in built in the software. The number of elements and nodes in each model are given in Table.2. FE models are shown in Fig. 5(b)-7(b)

Table.2 FE Parameters for all Specimens

\begin{tabular}{|c|c|c|c|}
\hline S.No & Specimen & No. of Elements & No. of Nodes \\
\hline 1 & Ring & 14149 & 17206 \\
\hline 2 & Triangle in Circle & 14937 & 17542 \\
\hline 3 & Square in Circle & 15028 & 17542 \\
\hline
\end{tabular}


Specimen 1: Circle in Circle (Ring)
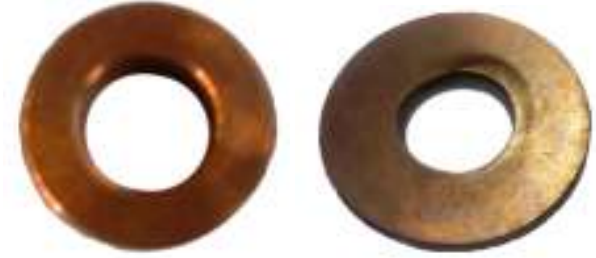

(a) Specimen before and after compression
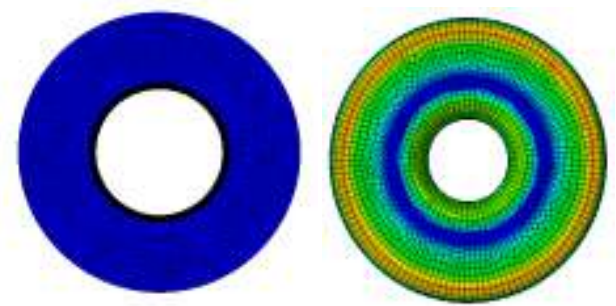

(b) FE model before and after compression

Fig.5: Specimen and FE model before and after compression

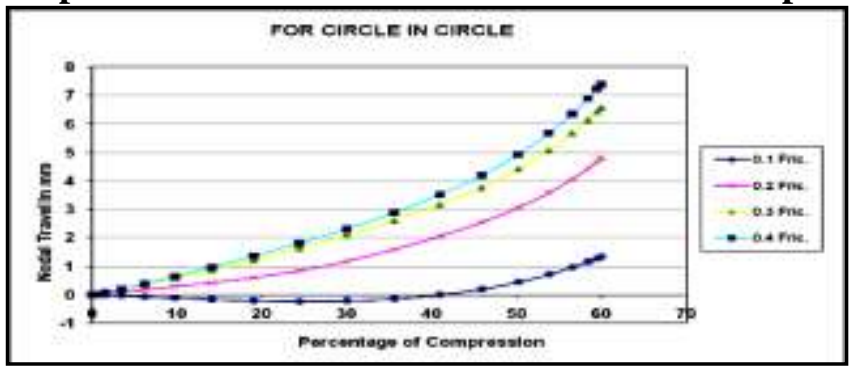

Graph.3: Friction Calibrattion Curve for Ring at 0.1 Fric., 0.2 Fric., 0.3 Fric.,0.4 Fric.

SPECIMEN 2: TRIANGLE IN CIRCLE
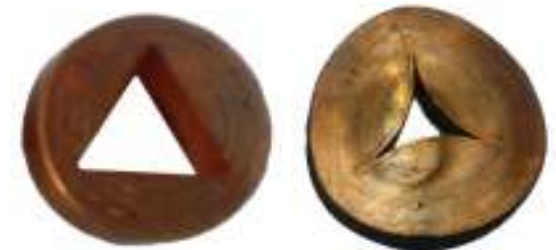

(a) Specimen before and after compression
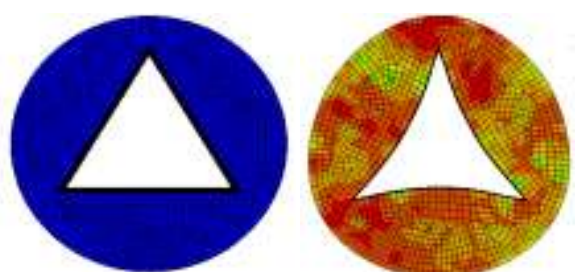

(b) FE model before and after compression 
Fig. 6: Specimen and FE model before and after compression

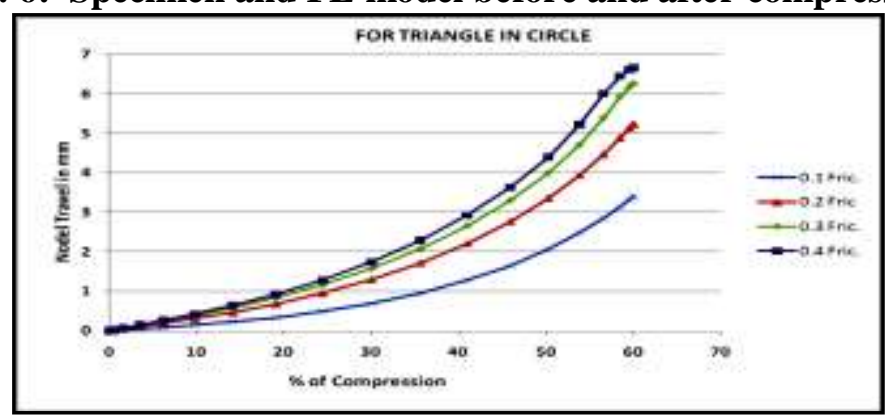

Graph.4: Friction calibration curve for Triangle in Circle Compression and Nodal travel data for $0.1,0.2,0.3,0.4$, Friction. SPECIMEN 3: SQUARE IN CIRCLE
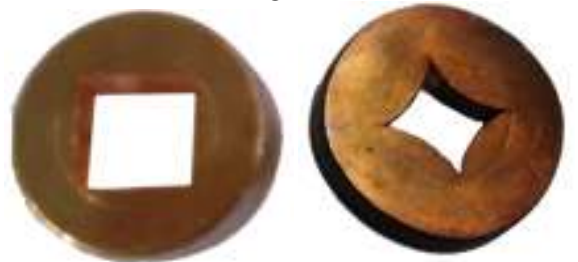

(a) Specimen before and after compression
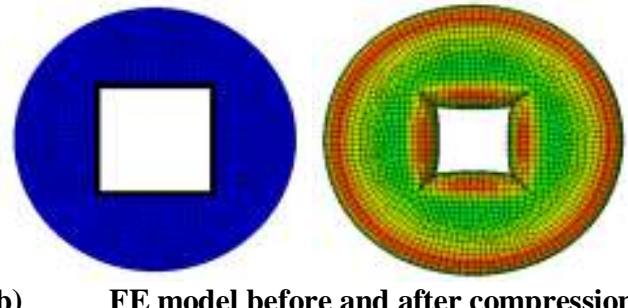

(b)

FE model before and after compression

Fig. 7: Specimen and FE model before and after compression

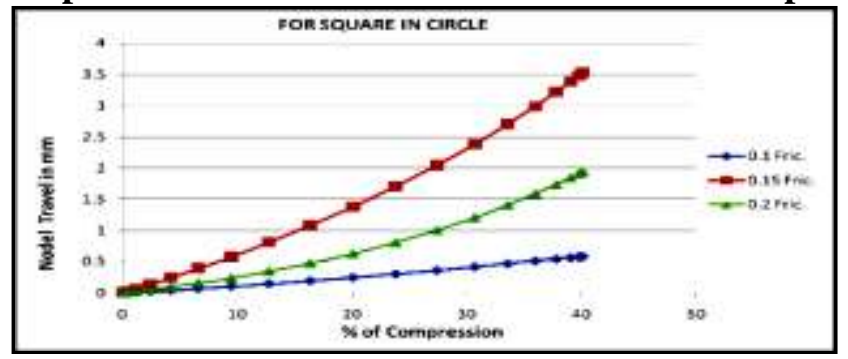

Graph.5: Show the friction calibration curve for Square in Circle for 0.1 Fric., 0.15Fric., 0.2 Fric.

\section{RESULTS}

Values of coefficient of friction, nodal travel for different specimens and stress developed are given in Table.3 Using the experimental results and calibration curves, friction is determined for different type of specimens. There are given in Table. 4 and compared to ring test results.

Table.3 The coefficient of friction values by FE simulation

\begin{tabular}{|c|c|c|c|c|c|}
\hline S.No & Specimens & $\begin{array}{c}\text { Stress } \\
\text { Develop } \\
(\mathrm{MPa})\end{array}$ & $\begin{array}{c}\text { Nodal Travels } \\
(\mathrm{mm})\end{array}$ & $\%$ of Compression & $\begin{array}{c}\text { Coefficient of } \\
\text { Friction }(\mu)\end{array}$ \\
\hline 1. & $\begin{array}{c}\text { Circle in Circle } \\
(\text { Ring })\end{array}$ & 581 & 0.5 & 40.61 & 0.13 \\
\hline 2. & Triangle in Circle & 602 & 1.23 & 41.54 & 0.13 \\
\hline 3. & Square in Circle & 538 & 1.63 & 41.54 & 0.14 \\
\hline
\end{tabular}


Table.4 Comparison of result with \% of error

\begin{tabular}{|c|c|c|c|c|}
\hline S.No & Specimens & $\begin{array}{c}\text { Standard Coefficient of } \\
\text { Friction }(\mu)(\text { By Ring) }\end{array}$ & $\begin{array}{c}\text { Calculated } \\
\text { Coefficient of Friction }(\mu)\end{array}$ & $\%$ Error \\
\hline 1. & Circle in Circle (Ring ) & 0.13 & 0.13 & 0 \\
\hline 2. & Triangle in Circle & 0.13 & 0.13 & 0 \\
\hline 3. & Square in Circle & 0.13 & 0.14 & 7.6 \\
\hline
\end{tabular}

V. CONCLUSION

In this study a search has been made to find alternative specimens for friction calibration using finite element simulation. Three specimens (one specimen is ring and two other different specimen) were tried for this purpose. Experimental work and FE Simulation on the above specimens are carried out. A ring of standard dimension is also tested in the same machine. When compared, standard ring specimen with other specimens, it is observed that the geometry of specimens which consist of any geometrical shape inside circle, give very close friction value. These specimens (who consist any geometry shape inside circle) can be used as a substitute to ring compression test for friction determination.

It is also observed that the length of side of specimens 2 and 3 (as triangle in circle and square in circle) remain same after the compression. Specimen 2 as triangle in circle is the best sample for determining the friction. Stress develops in this specimen is less than the ring specimen. Friction calibration curves for specimen 2 (triangle in circle) of the quite accurate results as compared to the ring compression test.

Hence, friction prediction become quite simple is using such specimens, especially in the absence of ring specimens.

\section{Reference}

[1] Kunogi, “A New Method of Cold Extrusion,” J. Sci. Research Inst.,Tokyo, Vol. 50, pp. 215-246, 1956

[2] Male, and Cockcroft, "A method for the Determination of the Coefficient of Friction of Metals Under Condition of Bulk Plastic Deformation," J. Inst. Met., Vol.93, pp. 38-46,1964-65

[3] Lee, Cheng I Weng and Jee Gong Chang, "A prediction of the friction factor for the forging process", Metallurgical and Materials Transactions B, Vol. 32, pp 137-143, 2001

[4] Bugini, Maccarini, Giardini, Pacaggnilla, and Levi, "The Evalution of Flow Stress and Friction in Upsetting of Rings and Cylinders", Annals of the CIRP, Vol. 42/1, pp. 335-338, 1993.

[5] Hayhurst, Chan, "Determination of friction models for metallic die work piece interfaces", International Journal of Mechanical Sciences, Vol. 47, pp. 1-25, 2005.

[6] Sofuoglu Hasan, Jahan Rasty, "Determination of friction coefficient utilizing the ring compression test", Journal of Engineering Materials and Technology, pp. 338-348, 2001

[7] User's manual, ABACUS software, 2011. 